Article

\title{
Drink Choice is Important: Beverages Make a Substantial Contribution to Energy, Sugar, Calcium and Vitamin C Intake among Australians
}

\author{
Malcolm D. Riley *(D, Gilly A. Hendrie and Danielle L. Baird \\ Commonwealth Scientific and Industrial Research Organisation (CSIRO) Health and Biosecurity, P.O. Box 10041, \\ Adelaide BC, SA 5000, Australia; Gilly.Hendrie@csiro.au (G.A.H.); Danielle.Baird@csiro.au (D.L.B.) \\ * Correspondence: Malcolm.Riley@csiro.au; Tel.: +61-8-8303-8989
}

Received: 21 May 2019; Accepted: 17 June 2019; Published: 20 June 2019

\begin{abstract}
It is important to understand the role of beverages in population dietary intake in order to give relevant advice. Population estimates were derived from one-day food recall dietary data from 12,153 participants in the 2011-2012 Australian National Nutrition and Physical Activity Survey. Almost all Australians (99.9\%) consumed at least one beverage on the day of the survey, accounting for $16.6 \%$ of the total energy intake for adults (aged 19 years and over) and $13.0 \%$ for children (aged 2-18 years). Similarly, beverages contributed 26-29\% to calcium intake, $22-28 \%$ to vitamin C intake, and $35-36 \%$ to sugar intake. Water was consumed on the day of the survey by $84.1 \%$ of Australian adults and $90.5 \%$ of children. For adults, the greatest beverage contributors to total energy intake were alcoholic drinks (5.6\%), coffee (3.1\%), and soft drinks $(1.9 \%)$, and for children, plain milk $(3.1 \%)$, flavoured milk $(2.8 \%)$, and fruit juice $(2.6 \%)$. Coffee $(10.6 \%)$ made the greatest contribution to calcium intake for adults; and plain milk (9.9\%) and flavoured milk (7.6\%) for children. The greatest contributors to vitamin $\mathrm{C}$ intake were fruit juice $(13.4 \%)$ and alcoholic drinks $(6.1 \%)$ for adults; and fruit juice $(23.4 \%)$ for children. For total sugar intake, soft drinks $(8.0 \%)$, coffee $(8.4 \%)$, and fruit juice $(5.9 \%)$ made the highest contribution for adults; and fruit juice $(9.8 \%)$ and soft drinks $(8.7 \%)$ for children. The type and amount of beverage consumption has considerable relevance to dietary quality for Australians.
\end{abstract}

Keywords: beverage intake; nutrient intake; Australian dietary survey; dietary energy intake; calcium intake; vitamin C intake; sugar intake; adults; children

\section{Introduction}

Beverage intake is frequently included in food-based national dietary guidelines. These guidelines provide context-specific and scientifically based recommendations for a health-promoting diet, responding to the public health and nutrition priorities and population consumption patterns, among other things [1]. A recent review of food-based dietary guidelines for countries on the North and South American continents [2] indicated that $90 \%$ of these guidelines (27 of 30) included recommendations about beverages, and half recommend drinking at least $2 \mathrm{~L}$ of water a day. An earlier review found that $79 \%$ of European countries included recommendations about beverages [3]. Previous research suggests there is significant variation in average beverage intake in relation to both the type and amount consumed within and between countries [4-6]. Unsurprisingly, the differences between countries appears to be reflected in the availability of beverage types in local supermarkets [7].

The current Australian Dietary Guidelines [8] recommend drinking plenty of water, as well as reduced fat milk and occasionally fruit juice. These guidelines also provide advice on limiting alcohol consumption and drinks that contain added sugars and salt. 
Beverages show a substantial diversity of energy, macronutrient, and micronutrient content [9], with some beverages containing specific bioactive constituents [10,11]. Comprehensive descriptive analyses of all beverage intake within a population are relatively infrequent and mainly oriented to assessing total water and energy intake [12-15] or association with other dietary components [16]. There has been some attention given to understanding categories of beverage intake such as sugar-sweetened beverages [17-21], sports and energy drinks [22,23], alcoholic beverages [24], $100 \%$ fruit juice $[25,26]$, and dairy drinks [27]. This is probably a consequence of interest in particular nutrients or components within these categories; however, consideration of all beverages gives greater clarity to the role of beverages and insight into their nutritional contribution to total intake.

The aim of this analysis was to examine the contribution of beverages and beverage sub-categories to total energy and selected nutrient intakes in the Australian population using data from the 2011-2012 National Nutrition and Physical Activity Survey.

\section{Materials and Methods}

\subsection{The Australian National Nutrition and Physical Activity Survey}

The Australian Health Survey (AHS) was conducted by the Australian Bureau of Statistics (ABS) in 2011-2013, reaching 32,000 people (25,000 households). The AHS is comprised of three components: the National Health Survey (NHS), the National Nutrition and Physical Activity Survey (NNPAS), and the National Health Measures Survey (NHMS). The secondary analysis conducted for this report utilised data collected from the 12,153 respondents completing the NNPAS.

A more detailed description of the sampling framework and data collection methods of the Australian Health Survey is available in the comprehensive 'Users Guide' accessible on the ABS website: http://www.abs.gov.au/ausstats/abs@.nsf/mf/4363.0.55.001.

Briefly, the method used to collect the dietary intake data as part of the NNPAS was two 5-phase, 24-h recalls where respondents were asked to recall the previous $24 \mathrm{~h}$ intake of food, beverages, and dietary supplements. The first recall was conducted face-to-face with a trained interviewer, and the second dietary recall was attempted with all respondents at least 8 days later via a telephone interview.

For children aged less than 15 years the interview was conducted primarily with a parent or guardian, and children were encouraged to participate. Parental consent was granted to interview respondents aged 15-17 years, while some parents opted to provide this information on the child's behalf.

To improve accuracy and quality of the data collected, interviewers used an Automated Multiple-Pass Method (AMPA) developed by the United States Department of Agriculture and adapted by the ABS together with Food Standards Australia and New Zealand (FSANZ) to better reflect the Australian food supply. This method attempts to maximise respondents' memory recall and was used in conjunction with a Food Model Booklet to assist respondents in the estimation of portion size and quantities of recalled items.

\subsection{Secondary Analysis Methodology}

All analyses were conducted using the first day of dietary recall (day 1 data) and excluded any nutrient intake originating from supplements. The second day of dietary recall was not used because only $64 \%$ of participants completed a second day recall. Results were predominantly grouped, and maintaining the integrity of one day of intake allows us to make valid comment on the range of intake on a day (i.e., the 10th to 90 th percentile).

Permission to access the survey database and to conduct this secondary analysis was obtained from the ABS prior to commencing the work.

The NNPAS dataset provides multiple lines of data, one for each food and beverage consumed at specific times across the day for each subject in the survey. Each food is identified by an 8-digit hierarchical food code that allows liquid foods to be distinguished by the first 3 digits of the code. 
A food combination code (combocode) identifies where separate food data lines were combined into a single food to be consumed (for example, milk and breakfast cereal into a single consumed food; coffee, sugar, and milk into a single consumed beverage). The first step of classifying beverage consumption was to identify and exclude liquids which were combined with other foods prior to consumption and consumed as a food, not beverage (for example wine added to a casserole). These were identified using the combocode and the specific time of consumption. The combocode was also used to re-join and correctly allocate liquids to a beverage category where more than one liquid was combined prior to consumption. For example, when vodka was mixed with orange juice, the combined beverage was categorised as an alcoholic beverage rather than fruit juice, and tea with added milk and sugar was combined and categorised as tea rather than plain milk or sugar.

Liquids that were not associated with a combocode were assumed to be consumed as a beverage. Each beverage including any additions was only accounted for once. There were 448 different beverages consumed by participants in the survey, each with an associated nutrient composition. All liquids were then categorised into a beverage category for analysis (Table 1).

Table 1. Description of beverage category membership.

\begin{tabular}{cl}
\hline Beverage Category & \multicolumn{1}{c}{ Description } \\
\hline Alcoholic beverages & $\begin{array}{l}\text { All beverages that include any alcohol content. Mixers were included in } \\
\text { the category, but any alcoholic beverage used as an ingredient in food } \\
\text { was not included. }\end{array}$ \\
\hline Tea & $\begin{array}{l}\text { All home-brewed tea plus all additions (milk, sugar, water) } \\
\text { were included. }\end{array}$ \\
\hline Coffee & $\begin{array}{l}\text { Hot coffee plus all additions (milk, sugar) were included. Cold } \\
\text { coffee-flavoured milk beverages were categorised as flavoured milks. }\end{array}$ \\
\hline Soft drink & $\begin{array}{l}\text { All flavoured carbonated beverages whether sugar-sweetened or } \\
\text { sweetened with other sweetening agents. Energy drinks were not } \\
\text { included. }\end{array}$ \\
\hline Cordial & All flavoured drinks made up with water from a concentrate. \\
\hline Energy drinks & All electrolyte ('sport' drinks) and energy drinks. \\
\hline Fruit juices & $\begin{array}{l}\text { All fruit and vegetable juices (non-carbonated), regardless of their } \\
\text { dilution. Includes infant drinks based on fruit or vegetables. }\end{array}$ \\
\hline Plain milk & $\begin{array}{l}\text { Plain white milk without flavouring or additives, regardless of fat } \\
\text { content. Milk used as an ingredient for food is not included; milk as an } \\
\text { ingredient of beverages was included in the respective categories. }\end{array}$ \\
\hline Flavoured milk & $\begin{array}{l}\text { All flavoured milk (hot or cold) whether as purchased or produced } \\
\text { through adding powdered or liquid flavouring to milk. }\end{array}$ \\
\hline Milk alternatives & $\begin{array}{l}\text { Plain or flavoured dairy milk alternatives such as soy milk and nut } \\
\text { milks. Not used in food or as an addition to other beverage category. }\end{array}$ \\
\hline Powdered flavourings with water, probiotic drinks, breakfast \\
cereal beverages.
\end{tabular}

Nutrient contribution was estimated from the individual beverage and aggregated for each participant into a beverage category or into beverages overall.

\subsection{Statistical Analysis}

Statistical analyses were performed using the IBM SPSS statistical software package version 23 (SPSS Inc., Chicago, IL, USA). Beverage consumption patterns were examined by gender (male, female, total) and by age $(2-3,4-8,9-13,14-18,19-30,31-50,51-70,71+$ years), as well as aggregated groups of children aged 2-18 years; adults aged $19+$ years, and total population $(2+$ years). For each beverage 
classification, estimates were calculated for the percent of the population group who consumed the beverage, the mean daily intake for all respondents who consumed any of the category on the surveyed day, and the 10th and 90th percentile of intake for the same group. If 20 subjects or less consumed from the beverage category for any demographic subgroup, no estimate for mean daily intake was calculated.

The contribution of beverages to total nutrient intake was estimated for energy intake, calcium, vitamin C, and total sugar intake, excluding nutrients from supplements. Estimates were calculated for consumers of each beverage category and for the total population within each demographic group.

Summary estimates were weighted to reflect the demographic structure of the Australian population using weights based on age, gender, and residential area that are included in the dataset by the Australian Bureau of Statistics. An additional weighting factor was applied to correct for the day of the week the survey was recorded for because the percentage of subjects reporting their intake for Saturday $(3.5 \%)$ and to a lesser extent Friday $(11.4 \%)$ were under-represented compared to the expected percentage of $14.3 \%$. The population weights were rescaled to the size of the sample for inferential statistics and calculation of $95 \%$ confidence limits for mean estimates.

The difference between males and females for mean beverage intake was tested for statistical significance using the Mann-Whitney U-test with no adjustment for multiple comparisons. The statistical difference between age groups was tested following a Kruskal-Wallis test using post hoc comparisons with Bonferroni adjustment. A chi-squared test was used to assess difference of proportions between categories. $p$-Values of less than 0.05 were taken as indicating statistical significance.

\section{Results}

\subsection{Assessment of Population Consumption}

Almost all survey subjects (99.9\%) reported consumption of one or more beverages during the day of the survey (Supplementary Table S1). The median daily number of beverage categories consumed per person was two for children and three for adults, and the 90th percentile for the number of daily beverage categories consumed was three for children and four for adults (data not shown). The median total beverage intake for the population was $1878 \mathrm{~g}$, with the 90th percentile being $3551 \mathrm{~g}$. The median total intake of beverages consumed was greater for adults than children (2061 g compared to $1275 \mathrm{~g}, p$ $<0.001$ ) and greater for males compared to females (2003 g compared to $1760 \mathrm{~g}, p<0.001$ ). After water (consumed by $84 \%$ of adults and $90.5 \%$ of children), the beverage categories consumed by the highest percentage of adults were coffee $(60.0 \%)$, tea $(48.3 \%)$, alcoholic drinks $(33.0 \%)$, and soft drinks $(26.7 \%)$; and for children were fruit juice $(38.7 \%)$, soft drinks $(28.3 \%)$, plain milk $(28.1 \%)$, and flavoured milk (20.8\%). Energy drinks, other beverages, and milk alternatives were consumed by less than $5 \%$ of adults, and coffee, energy drinks, milk alternatives, and alcoholic drinks were consumed by less than $5 \%$ of children. A higher percentage of adult men than women consumed alcoholic beverages ( $41 \%$ compared to $26 \% ; p<0.001$ ) and soft drinks ( $30 \%$ compared to $24 \% ; p<0.001$ ), but a higher percentage of women consumed tea (55\% compared to $41 \% ; p<0.001)$. Differences in the percentage of males and females consuming different beverage categories was less pronounced in children.

Beverage intake accounted for $15.8 \%$ of energy on average across the population. The contribution of beverages to total energy was highest in children aged $2-3$ years (16.0\% of energy), and in the $19-30$ and $31-50$ year adult age groups (17.1\% and $17.5 \%$ of energy, respectively). For every age group examined, the contribution of beverages to total energy exceeded $10 \%$ of total energy intake and was greater than $15 \%$ for all adults aged 19 to 70 years (Figure 1). Adult men, compared to adult women, consumed a significantly greater proportion of their energy intake as a beverage; this was consistent across all adult age groups (Figure 2). This was also consistent with adult men having a higher average daily amount of every beverage category compared to women except for tea (Supplementary Table S1). The beverage categories that made the greatest contribution to total dietary energy intake were alcoholic drinks (5.6\%) and coffee (3.1\%) for adults; and plain milk (3.1\%), flavoured milk $(2.8 \%)$, fruit juice $(2.6 \%)$, and soft drinks (2.1\%) for children (Figure 3 ). 


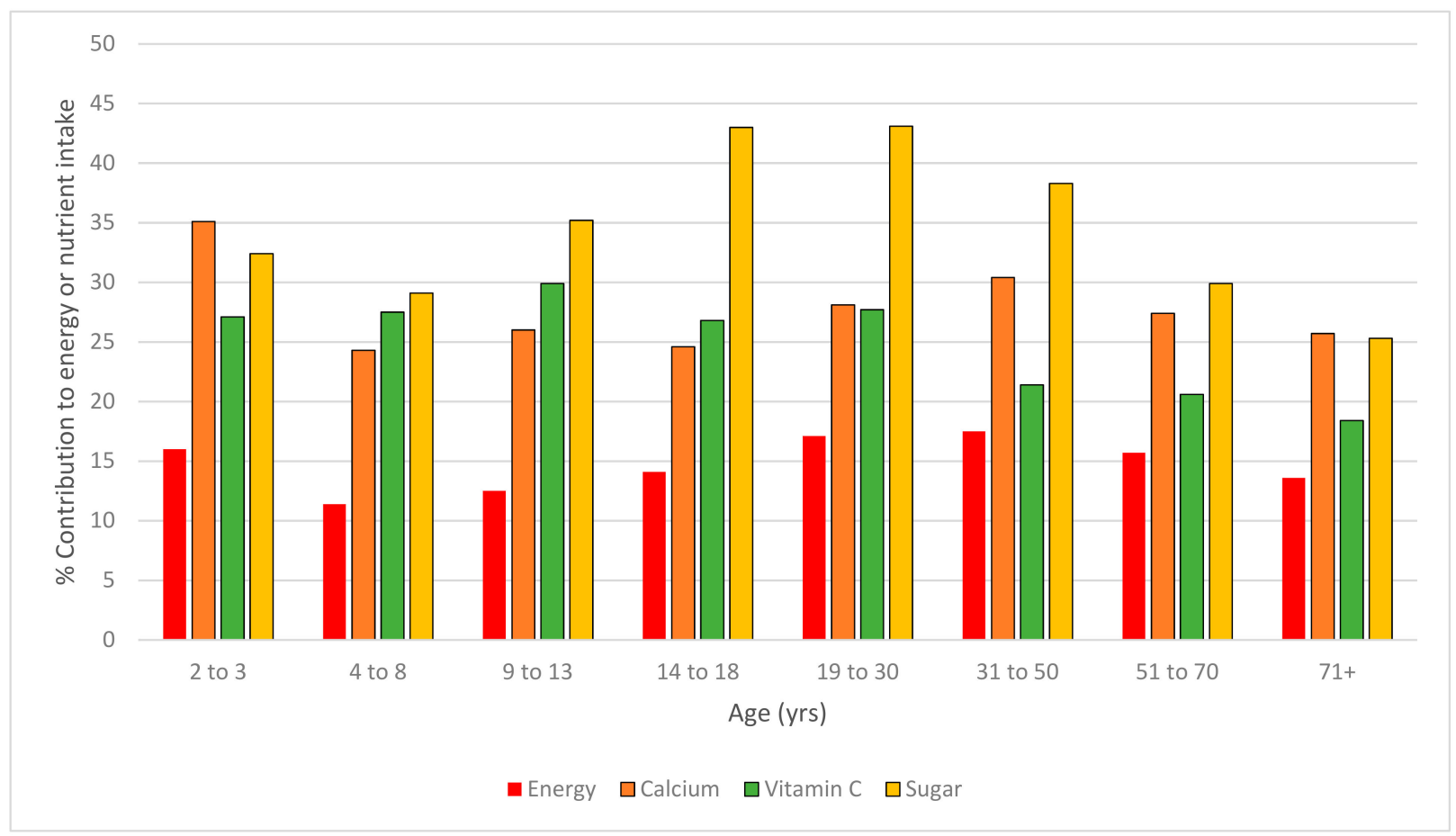

Figure 1. The percentage contribution of total beverage intake to total dietary energy, calcium, vitamin C, and sugar intake by age group. 


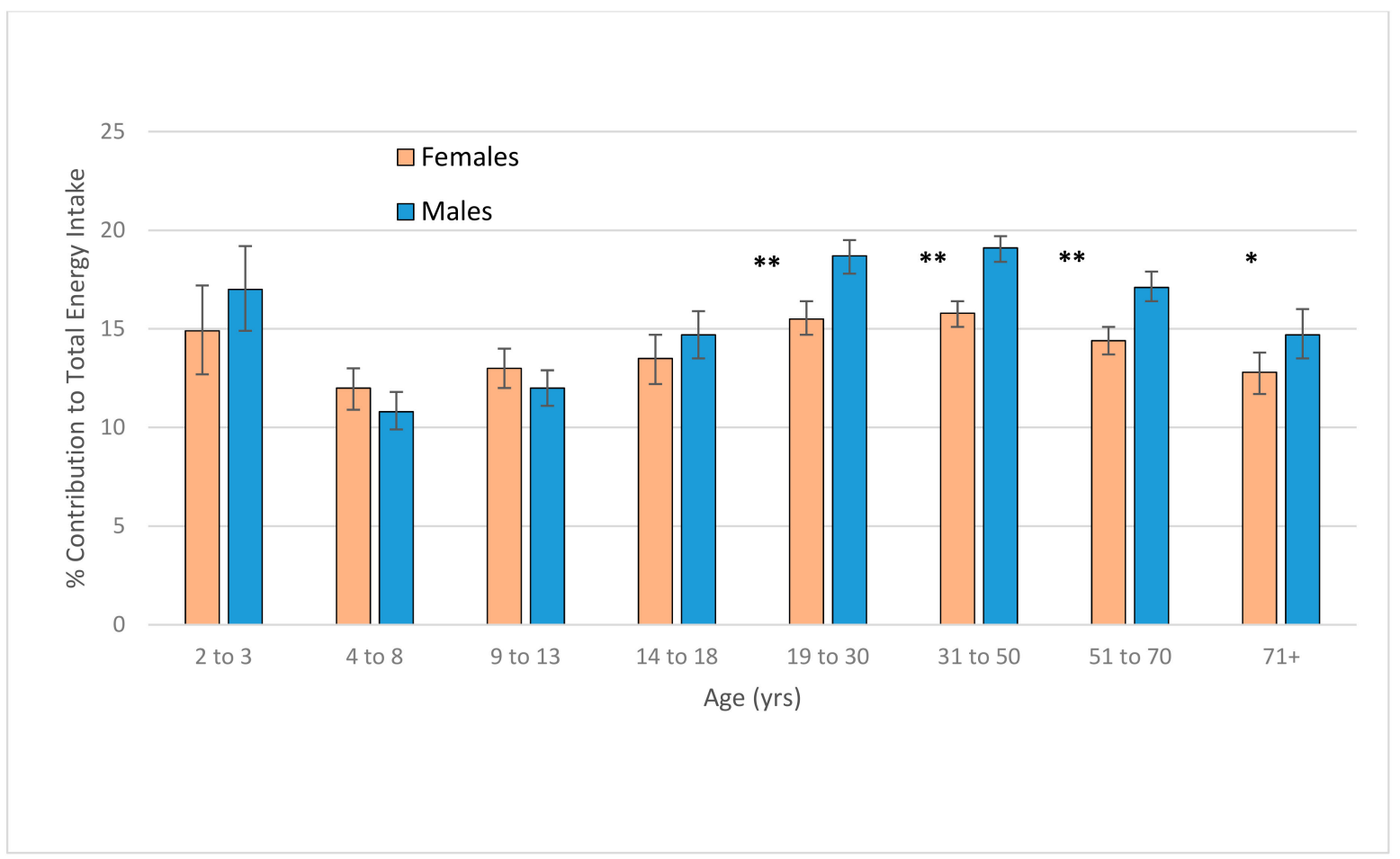

Figure 2. The percentage contribution (mean $\pm 95 \%$ confidence interval $[\mathrm{CI}]$ ) of total beverage intake to total dietary energy intake for Australians by age group and sex. * Difference between males and females statistically significant at $p=0.01$; ** Difference between males and females statistically significant at $p<0.001$. 

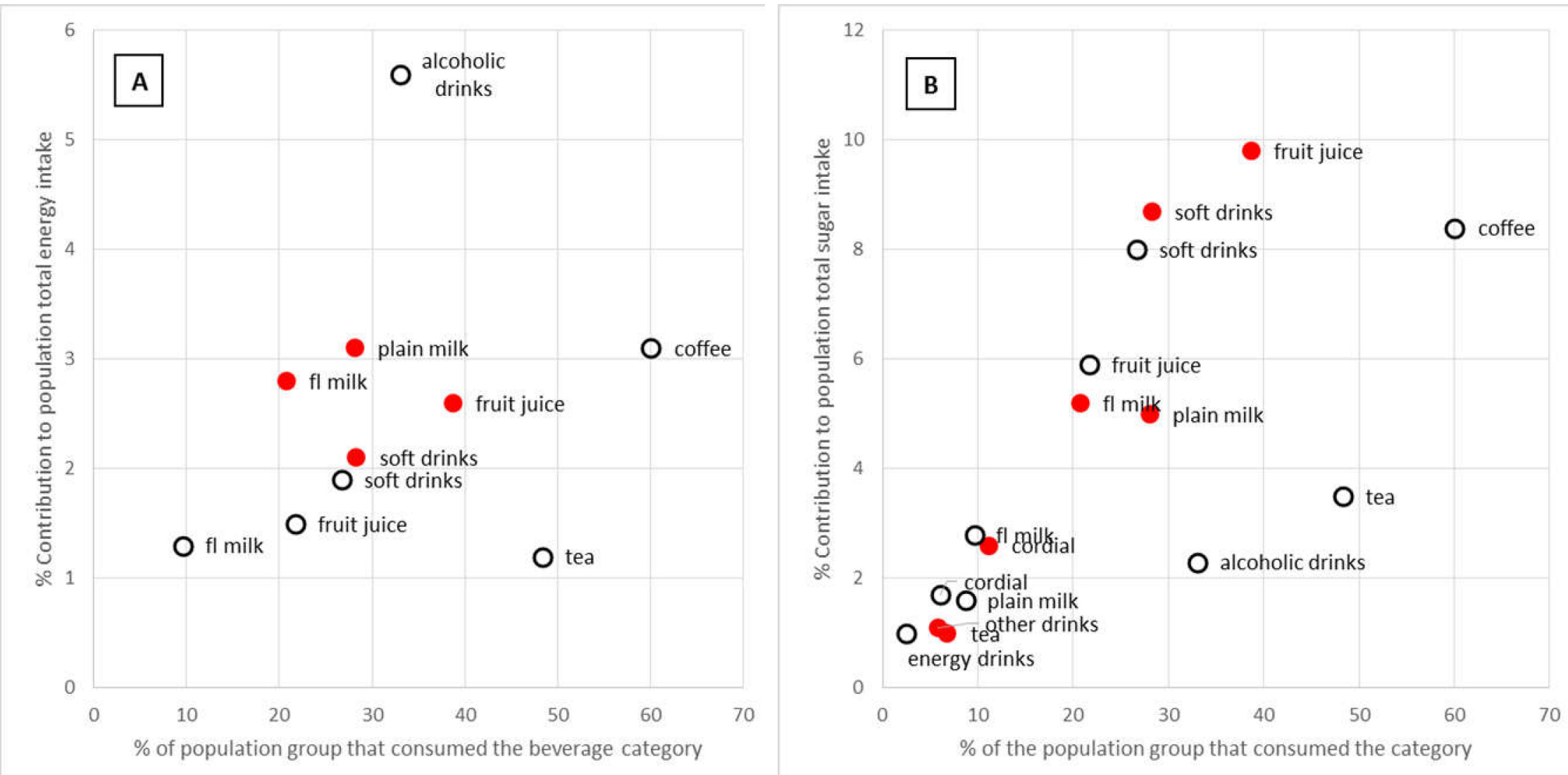

Figure 3. The contribution of beverage categories to (A) total dietary energy intake and (B) total sugar intake for Australian children (2 to 18 years, are shown. 
The contribution of beverages to total dietary sugar intake (without distinction between natural or added sugars) is also shown in Figure 1. The largest contribution of beverages to dietary sugar intake was for the 14-18 years and 19-30 years age groups where beverage intake contributed $43 \%$ of the total dietary sugar intake. For all age groups, beverage intake contributed more than $25 \%$ of dietary sugar intake. The beverage categories that made the greatest contribution to total sugar intake were coffee $(8.4 \%)$, soft drinks $(8.0 \%)$, fruit juice $(5.9 \%)$, tea $(3.5 \%)$, flavoured milk $(2.8 \%)$, and alcoholic drinks $(2.3 \%)$ for adults; and fruit juice $(9.8 \%)$, soft drinks $(8.7 \%)$, flavoured milk (5.2\%), plain milk (5\%), and cordial (2.6\%) for children (Figure 3).

For every age group, the percentage contribution of beverages to calcium intake and vitamin $\mathrm{C}$ intake was greater than its contribution to energy intake (Figure 1). For children aged 2-3 years, beverages made the greatest contribution to calcium intake (35.1\%), but the contribution of beverages to calcium intake was almost, or above, $25 \%$ for all age groups. The beverage categories that made the greatest contribution to calcium intake were coffee (10.6\%), flavoured milk (3.6\%), tea (3.3\%), and plain milk $(2.9 \%)$ for adults; and plain milk $(9.9 \%)$ and flavoured milk $(7.6 \%)$ for children (Figure 4$)$.

The contribution of beverages to total vitamin $C$ was above $20 \%$ for all age groups except the oldest adult age group (71 years and older). Beverages made the greatest contribution to vitamin $C$ intake for children aged 9-13 years, where almost $30 \%$ of total vitamin C intake was from beverages. Beverage categories with the highest contribution to vitamin $C$ intake were fruit juice $(13.4 \%)$ and alcoholic drinks (6.1\%) for adults; and fruit juice (23.4\%) and flavoured milk (2.2\%) for children (Figure 4). 

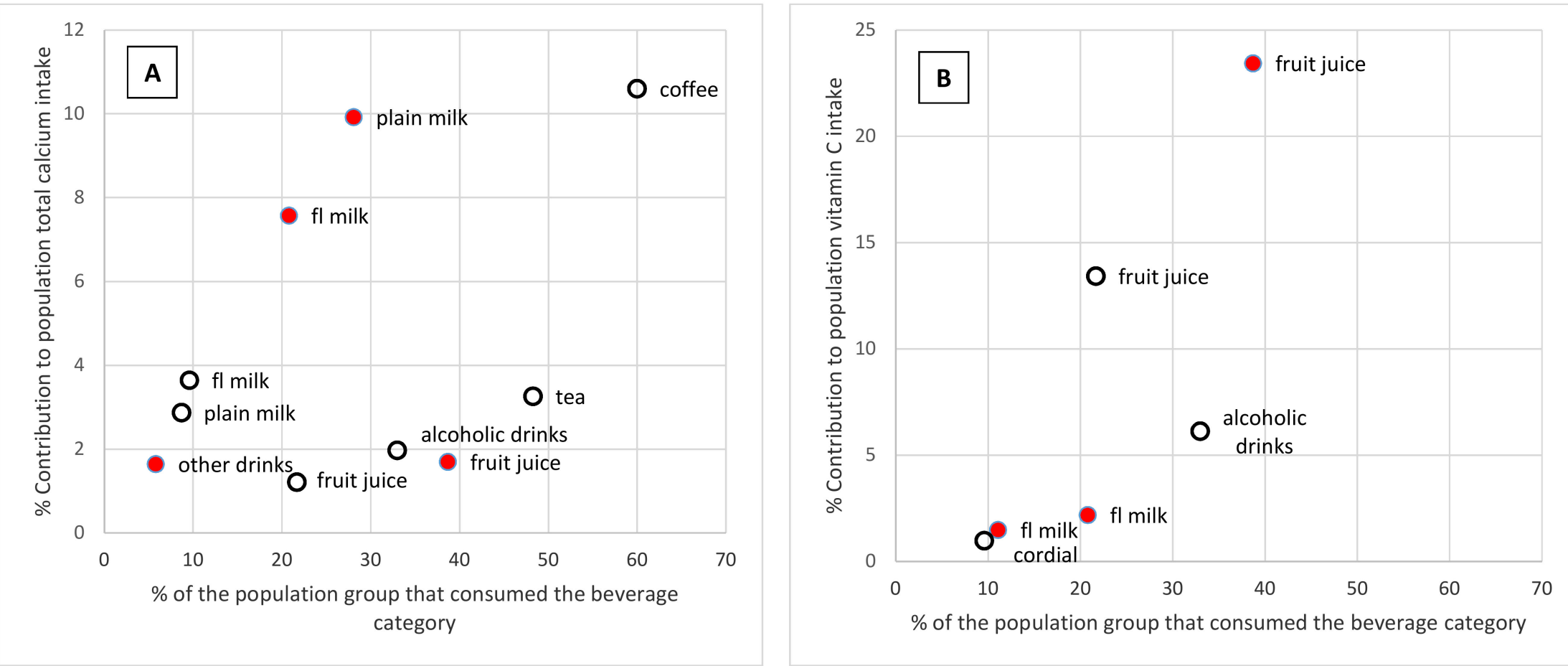

Figure 4. The contribution of beverage categories to (A) total dietary calcium intake and (B) total dietary vitamin C intake for Australian children (2 to 18 years, and adults (19 years and older, $\mathrm{O}$ ) by the prevalence of consumption on the day of the survey. Only categories contributing $1 \%$ or more to the total nutrient intake are shown. 


\subsection{Assessment of Consumption by Consumers Only}

The contribution of a beverage category to total energy or nutrient intake of the population is related to its composition, the percentage of the population who consumed it, and the mean amount consumed (in addition to other dietary sources of energy or nutrient intake). When the dietary intake is assessed only for those persons who consumed a beverage from the category, the contribution of the beverage category to mean total intake is higher (Supplementary Table S2). For adults who consumed tea on the day of the survey, it contributed an average of $2.7 \%$ to their total energy intake, but $7.1 \%$ to their total calcium intake and $7.6 \%$ to their total sugar intake. For adults who consumed one or more alcoholic drinks, this category contributed a mean of $17.1 \%$ to total energy intake, $18.7 \%$ to total vitamin $C$ intake, and $6.9 \%$ to total sugar intake. For children who consumed fruit juice on the day of the survey, it contributed $60.1 \%$ to their total vitamin C intake, $25.2 \%$ to their total sugar intake, but only $6.6 \%$ to their total energy intake. Similarly for children who consumed flavoured milk on the day of the survey, it contributed $39.7 \%$ to their total calcium intake, $27.4 \%$ to their total sugar intake, and only $14.5 \%$ to their total energy intake.

The mean daily intake for consumers of water (983 $\mathrm{g}$ for child consumers, $1302 \mathrm{~g}$ for adult consumers) and of alcoholic drinks (862 $\mathrm{g}$ for child consumers [mostly males aged 14-18 years]; $806 \mathrm{~g}$ for adult consumers) is much higher than other beverage categories ( Supplementary Table S1). For adult consumers, the mean daily intake of soft drinks, tea, coffee, and flavoured milk is between $400 \mathrm{~g}$ and $600 \mathrm{~g}$, and for consumers of cordial and energy drinks, it was marginally higher (606 $\mathrm{g}$ to $633 \mathrm{~g}$ ). The mean daily intake for adult consumers of fruit juice, milk, and milk alternatives is between $250 \mathrm{~g}$ and $400 \mathrm{~g}$, with other beverages lower at $228 \mathrm{~g}$. For child consumers, the mean daily intake of each of cordial, soft drink, flavoured milk, and tea is between $350 \mathrm{~g}$ and $500 \mathrm{~g}$, with the mean daily intake of consumers for energy drinks being higher $(541 \mathrm{~g})$. The mean daily intake for child consumers of fruit juice, milk, coffee, and milk alternatives is between $250 \mathrm{~g}$ and $350 \mathrm{~g}$; and with other beverages it is lower at $166 \mathrm{~g}$. Most of the child consumers of coffee and energy drinks were aged 14-18 years, and there was a tendency for consumers of soft drinks and tea to be from older age categories (Supplementary Table S1).

\section{Discussion}

Beverages are an important component of the dietary intake of Australians, providing $13.0 \%$ of total dietary energy for children and $16.6 \%$ of energy for Australian adults. A high prevalence [28] of body fatness in Australian children aged 5 to 17 years $(24.9 \%)$ and adults $(67 \%)$ means that energy over-consumption is a general dietary concern and must include beverage intake. To date, there has been considerable attention on specific categories of beverages, such as sugar-sweetened beverages and water, to support specific public health campaigns, but to our knowledge, this is the first examination of the role of all beverages to daily intakes of energy and nutrients. While making a substantial contribution to energy and sugar intake, beverages also contributed more than $25 \%$ of the total intake of calcium and more than $23 \%$ of vitamin $C$ for both adults and children. Beverages are included in population dietary guidelines in most countries around the world, so it is important that their use is understood, for both the positive and negative aspects, in the context of the overall dietary pattern.

Similar to food consumption, beverage consumption differed by age and gender. For adults, the most commonly consumed beverages other than water were coffee and tea, alcohol, and soft drinks. However, as a consequence of energy density and the volumes consumed, the contribution to total energy intake was highest for alcohol, followed by coffee and soft drinks. Notably, the percentage contribution of beverage intake to total energy intake was higher for adult men than women. The population prevalence of beverage consumption for men was higher by at least $5 \%$ than women for soft drinks and alcohol, while for women it was at least $5 \%$ higher for tea and water. Furthermore, the mean amount consumed by adult male consumers was at least $100 \mathrm{~g}$ higher for cordial, soft drinks, energy drinks, plain milk, alcohol, and water compared to women. Within categories, drink types consumed by men and women may have different caloric values-for example, women consumed white wine 
more than other alcoholic drinks while men consumed beer [24]-however, the differences in intake for the specific beverage categories between men and women are large. Almost all of the adult men and women had a beverage on the day of the survey, yet the contribution of beverages for women to their smaller total energy intake was at least two percentage points lower for all age groups.

Australian children most commonly consume fruit juice, soft drink, plain, and flavoured milks, and each category provided between $2-3 \%$ of children's total energy. Fruit juice also provided 22-25\% of children's total vitamin $C$ intake depending on age group and up to $60 \%$ of total vitamin $C$ among fruit juice consumers. While vitamin $C$ is not generally regarded as a nutrient at risk of deficiency in the Australian population, and non-beverage sources are readily available (fresh fruit and vegetables for example), less than $6 \%$ of the adult population consume fruits and vegetables in the amounts recommended [28]. Furthermore, a recent South Australian study [29] measured serum vitamin C levels in 149 hospitalized elderly patients with $76.5 \%$ having hypovitaminosis C. The authors suggested the results might be indicative of a high prevalence of vitamin $C$ deficiency in the community and recommended community surveys. Consumption of fruit juice is more prevalent in children than adults.

Calcium is a nutrient for which subgroups of the population are recognized to have intakes below recommendations. Not accounting for supplement intake, across age groups, 43-94\% of Australian adults and $11-94 \%$ of children aged 4 years and above don't meet the estimated average requirement (EAR) for calcium [30], therefore the contribution from beverages is important in the context of overall intake. Beverages provide almost one quarter or more of total calcium intake from food for each of the age groups. Unsurprisingly, milk and beverages containing milk made a strong contribution to calcium intake in adults and children. For adults, coffee contributed almost three times more to calcium intake than milk, flavoured milk, or tea (10.6\% compared to $2.9 \%, 3.6 \%$, and $3.3 \%$, respectively); while for children, plain milk (9.9\%) and flavoured milk (7.6\%) were the major contributors.

The percentage of Australian children consuming plain or flavoured milk as a beverage was similar-28\% of children consumed plain milk and 21\% consumed flavoured milk. Using a 2007 national survey of children aged 2-16 years [31], the percentage of Australian children who consumed plain and flavoured milk was $65 \%$ or more for plain and $10 \%$ or less for flavoured, depending on age. A critical methodological difference was that the earlier analysis examined dairy foods as any part of intake (not only beverages) and defined flavoured milk as pre-mixed flavoured milks only while categorising milk with flavouring added in the plain milk category. In the present survey, the prevalence of intake of flavoured milk (home prepared and commercial) as a drink is higher than that of plain milk as a drink for the age groups 9-13 years and 14-18 years. Children offered flavoured milk have a higher overall milk intake than children drinking plain milk only with consequent nutritional benefits [32]. While added sugar intake for children should be discouraged, offering non sugar-sweetened flavoured milk may be a useful strategy to increase dairy food and calcium intakes in older children who do not generally meet their dietary recommendation [31].

Policy development specifically to reduce sugar sweetened beverage intake has been called for by many investigators [33-37] to reduce sugar and energy intake, although it has been acknowledged that targeting only beverages is an inappropriate policy response [35]. The present analysis found the contribution of beverages to total sugar intake was greater than $25 \%$ for all age groups, peaking at more than 40\% for the 14-18 year and the 19-30 year age groups. Soft drinks and fruit juice were strong contributors to sugar intake for both adults and children, with coffee also making a substantial contribution for adults (6.7\%) and flavoured milk and plain milk for children (5.2\% and $5.0 \%$ respectively). Analyses of free or added sugars $[35,38]$ highlight the contribution from soft drinks and fruit juice but largely overlook the sugar contribution from coffee and milk-based drinks because the intrinsic sugar in milk is not defined as a free or added sugar. Soft drinks, while the highest ranking beverage category in dietary sugar contribution for adults ( $8 \%$ ), rank third (at $1.9 \%)$ behind alcoholic drinks and coffee in contribution to dietary energy intake. To strengthen an effort at the individual 
or population level to decrease overall energy intake from beverages, it is rational to also take into consideration beverages other than sugar sweetened soft drinks.

Consistent with the Australian Dietary Guideline recommendation to drink "plenty of water", the water category was consumed by the highest percentage of Australians and in the highest daily amount. Water was consumed by more than $85 \%$ of people on the surveyed day, and the average daily intake for consumers was $1227 \mathrm{~g}$. This is not necessarily a universal finding. For example, a large Dutch cohort of men and women aged 55-69 years old [39] found that mean water intake was only $95 \mathrm{~mL} / \mathrm{day}$, and $53 \%$ of men and $43 \%$ of women stated that they did not consume water at all. In the United States, while beverages provide 76-83\% (according to age group) of total water intake for adults, older adults have been identified as potentially not consuming enough water [40]. In France [41], water intake is associated with higher dietary quality and lower intake of other beverages, in particular tea and coffee (although alcohol intake was not included in the analysis). In a randomised controlled trial setting [42], those achieving a high water intake (as a beverage) also had a greater increase in fruit and vegetables, as well as a greater decrease in salty snacks, cakes, and cookies. An increased water intake has also been implicated as assisting with weight loss or weight maintenance [43,44]. An intervention to increase water intake would be relatively simple and low cost, although a large community-based randomised controlled trial showed a better result on weight loss when diet beverages were increased compared to water [45].

The Australian Dietary Guidelines also advise "if you choose to drink alcohol, limit intake". These guidelines and Australian alcohol guidelines (www.alcohol.gov.au) state that alcoholic drinks are not recommended for children, and adults are recommended to have no more than 2 standard (alcoholic) drinks on any day to reduce the risk of harm from alcohol-related disease or injury over a lifetime. In other analysis of the same survey [24], the median alcohol intake of adult men consumers was 3.3 standard drinks on weekdays and 4.1 on weekend days. For adult women consumers, the median intake was 2.7 standard drinks on weekdays and 3.1 on weekend days. From this analysis, the 90th percentile of intake was more than $1.8 \mathrm{~L}$ of alcoholic beverage. Even allowing for misreporting of alcoholic beverage intake, most Australian drinkers of alcoholic beverages exceed the recommended alcohol intake guidelines.

Mean beverage intake and the mean intake of different drink types varies considerably between countries for both children and adults $[4-6,46]$. Some countries have a substantially lower contribution of beverages to total energy intake (for example, 6\% in Italy for 2005-2006, 8\% in France for 2009, and $12 \%$ in Spain for 2013) [46]. The regional diversity highlights that national beverage intake is probably readily modifiable.

Comparison of beverage intake of Australians over time is problematic due to the small number of national surveys and differences in survey methodologies. Other data are available, such as sales data. In Australia, sales trends of non-alcoholic, water-based, ready-to-drink beverages were examined for the period 1997-2011 [47]. Sugar-sweetened carbonated soft drink sales declined from 75.8 to $56.1 \mathrm{~L}$ per person between 1997 and 2011, whereas non-sugar carbonated soft drink purchases increased from 22.8 to $28.2 \mathrm{~L}$ per person. Sales of still water increased by $12.4 \mathrm{~L}$ per person. The analysis did not cover all beverage types, reflected sales data rather than intake, and excluded tap water intake, therefore it is unclear whether total volume of beverage intake in Australia has changed. However, it is consistent with a large survey in South Australia [48] indicating a decrease in soft drink consumption between 2008 and 2013 among adults. These data show the consumption of soft drinks by Australians may be declining, led by sugar-sweetened soft drinks. It is reasonable to conclude that overall beverage choices have changed for Australians over a relatively short time period, possibly in a health-promoting direction. It is therefore somewhat realistic to expect that the Australian population could undertake beverage substitution to beverages that are better for them or otherwise reduce their intake of undesirable beverages [49]. In fact, the pleasure resulting from beverage consumption may not depend on the amount consumed [50] or the type of beverage consumed; perceived health impact may be a motivator for beverage consumption on at least some occasions. 
A strength of this secondary analysis is that it is based on large sample national dietary survey data with a moderately high response rate, therefore minimising the effect of non-response bias. The results are weighted to reflect the Australian population but also for day of the week to adjust for the disproportionate representation of certain days of the week due to the practicalities of collecting survey data. This is important given differences in beverage intake have been observed between week days to week-end days (e.g., [12,24]). Another strength of this study is the inclusion of all beverage categories, as well as the identification and exclusion of liquids that are combined with other foods and consumed as a food (in the example of milk added to cereal). This seems a sensible approach, because foods that are consumed as drinks are cognitively, functionally, and perhaps different in their physiological effect to foods that are eaten. However, the reasons that all drinks have not been commonly examined may be because researchers have a specific interest in one or few beverage categories, the technical difficulties in distinguishing drinks from foods eaten in large dietary datasets, and the fact that alcoholic drinks may be considered a special category of food that should be considered separately. This approach to dietary analysis has allowed for a comprehensive understanding of the role of beverages in the Australian diet. Limitations of the present study warrant discussion. Dietary survey data using $24 \mathrm{~h}$ recall are likely to under-report true dietary intake based on analysis of energy requirement [51,52], and misreporting may occur differentially between different foods and between foods and drinks. One $24 \mathrm{~h}$ dietary recall was used to assess the usual group intake because it maximized the number of participants included (only $64 \%$ of participants completed a second $24-\mathrm{h}$ recall, and by telephone). The reported individual intakes represent beverage intake on a day, not usual beverage intake; however, the mean of the individual intakes for groups is a good representation of mean usual intake [53]. For this analysis, we used a range of broad categorisations of beverages, and while we described intake across 12 categories, further categorisation would provide finer detail. The categorisation of drinks requires subjective choices to be made which may not suit every purpose. In this analysis, soft drinks were categorised separately to energy drinks because of an expected different pattern of intake [22,23], and fruit juices included diluted fruit juices as well as pure fruit juices. These categories provide more detail than some previous; however, other investigators may have made other choices.

\section{Conclusions}

Beverages make an important contribution to the dietary energy intake of Australians (16\%) and contribute more than a third to total sugar intake. Beverages also contribute about a quarter to total calcium and vitamin $C$ intakes. The most commonly consumed beverage category is water, which was consumed by more than $85 \%$ of Australians on the day of the survey. For adults, the highest contributors to energy intake were alcohol and coffee, while for children, plain and flavoured milk and fruit juice were the highest contributors. Judicious beverage choice should aim to maximise its nutrient contribution while (for many people) considering its energy contribution.

Supplementary Materials: The following are available online at http://www.mdpi.com/2072-6643/11/6/1389/s1, Table S1: Mean beverage intake $(\mathrm{g})$ and 10th, 90th percentile for those who consumed any of the beverage category on the day of the survey, Table S2: Percentage contribution to energy, calcium, vitamin C, and total sugar intake for those who consumed the beverage (i.e., on the day that food intake was measured) and for the population.

Author Contributions: Conceptualization, M.D.R., G.A.H., and D.L.B.; Data curation, D.L.B.; Formal analysis, M.D.R. and D.L.B.; Funding acquisition, M.D.R.; Methodology, M.D.R., G.A.H., and D.L.B.; Project administration, M.D.R.; Visualization, G.A.H.; Writing—original draft, M.D.R.; Writing—review and editing, M.D.R., G.A.H., and D.L.B.

Funding: The Australian Beverages Council Limited (ABCL) part-funded the secondary analyses of the 2011-2012 NNPAS outlined in this manuscript, after funding a comprehensive analysis by the authors of water based beverages using data from the same survey.

Acknowledgments: The Australian Bureau of Statistics conducted the National Nutrition and Physical Activity Survey 2011-2012 and made the data available for this secondary analysis. The staff who conducted the survey and the survey participants are gratefully acknowledged. 
Conflicts of Interest: The authors declare no conflicts of interest. The ABCL had no part in the design of the analyses, interpretation, writing, or editing of the manuscript. Conclusions and opinions expressed remain the responsibility of the authors.

\section{References}

1. FAO/WHO. Historical Overview of Food-based Dietary Guidelines. In FAO/WHO Technical Consultation on National Food-Based Dietary Guidelines; FAO/WHO: Cairo, Egypt, 2004; pp. 7-8. Available online: http://www.fao.org/3/ai216e/ai216e.pdf (accessed on 15 April 2019).

2. Montagnese, C.; Santarpia, L.; Iavarone, F.; Strangio, F.; Caldera, A.R.; Silvestri, E.; Contaldo, F.; Pasanisi, F. North and South American countries food-based dietary guidelines: A comparison. Nutrition 2017, 42, 51-63. [CrossRef] [PubMed]

3. Montagnese, C.; Santarpia, L.; Buonifacio, M.; Nardelli, A.; Caldera, A.R.; Silvestri, E.; Contaldo, F.; Pasanisi, F. European food-based dietary guidelines: A comparison and update. Nutrition 2015, 31, 908-915. [CrossRef] [PubMed]

4. Singh, G.M.; Micha, R.; Khatibzadeh, S.; Shi, P.; Lim, S.; Andrews, K.G.; Engell, R.G.; Ezzati, M.; Mozzafarian, D. Global Burden of Diseases Nutrition and Chronic Diseases Expert Group (NutriCoDe). Global, regional and national consumption of sugar-sweetened beverages, fruit juices and milk: A systematic assessment of beverage intake in 187 countries. PLoS ONE 2015, 10, e0124845. [CrossRef] [PubMed]

5. Guelinckx, I.; Ferreira-Pêgo, C.; Moreno, L.A.; Kavouras, S.A.; Gandy, J.; Martinez, H.; Bardosono, S.; Abdollahi, M.; Nasseri, E.; Jarosz, A.; et al. Intake of water and different beverages in adults across 13 countries. Eur. J. Nutr. 2015, 54, 45-55. [CrossRef] [PubMed]

6. Guelinckx, I.; Iglesia, I.; Bottin, J.H.; De Miguel-Etayo, P.; González-Gil, E.M.; Salas-Salvadó, J.; Kavouras, S.A.; Gandy, J.; Martinez, H.; Bardosono, S.; et al. Intake of water and beverages of children and adolescents in 13 countries. Eur. J. Nutr. 2015, 54, S69-S79. [CrossRef]

7. Chepulis, L.; Mearns, G.; Hill, S.; Wu, J.H.Y.; Crino, M.; Alderton, S.; Jenner, K. The nutritional content of supermarket beverages: A cross-sectional analysis of New Zealand, Australia, Canada and the UK. Public Health Nutr. 2018, 21, 2507-2516. [CrossRef]

8. National Health and Medical Research Council. Australian Dietary Guidelines; National Health and Medical Research Council: Canberra, Australia, 2013.

9. Popkin, B.M.; Armstrong, L.E.; Bray, G.M.; Cabellero, B.; Frei, B.; Willett, W.C. A new proposed guidance system for beverage consumption in the United States. Am. J. Clin. Nutr. 2006, 83, 529-542. [CrossRef]

10. Khan, N.; Mukhtar, H. Tea polyphenols in promotion of human health. Nutrients 2019, 11, 39. [CrossRef]

11. Rampersaud, G.C.; Valim, M.F. $100 \%$ citrus juice: Nutritional contribution, dietary benefits, and association with anthropometric measures. Crit. Rev. Food Sci. Nutr. 2017, 57, 129-140. [CrossRef]

12. Gibson, S.; Shirreffs, S.M. Beverage consumption habits "24/7" among British adults: Association with total water intake and energy intake. Nutr. J. 2013, 12, 9. [CrossRef]

13. Sui, Z.X.; Zheng, M.; Zhang, M.; Rangan, A. Water and beverage consumption: Analysis of the Australian 2011-2012 National Nutrition and Physical Activity Survey. Nutrients 2016, 8, 678. [CrossRef] [PubMed]

14. Ng, S.W.; Ni Mhurchu, C.; Jebb, S.A.; Popkin, B.M. Patterns and trends of beverage consumption among children and adults in Great Britain, 1986-2009. Br. J. Nutr. 2012, 108, 536-551. [CrossRef] [PubMed]

15. Stern, D.; Piernas, C.; Barquera, S.; Rivera, J.A.; Popkin, B.M. Caloric beverages were major sources of energy among children and adults in Mexico, 1999-2012. J. Nutr. 2014, 144, 949-956. [CrossRef] [PubMed]

16. Sui, Z.X.; Wong, W.K.; Louie, J.C.Y.; Rangan, A. Discretionary food and beverage consumption and its association with demographic characteristics, weight status, and fruit and vegetable intakes in Australian adults. Public Health Nutr. 2017, 20, 274-281. [CrossRef]

17. Hoare, E.; Varsamis, P.; Owen, N.; Dunstan, D.W.; Jennings, G.L.; Kingwell, B.A. Sugar- and intense-sweetened drinks in Australia: A systematic review on cardiometabolic risk. Nutrients 2017, 9, 1075. [CrossRef] [PubMed]

18. Pollard, C.M.; Meng, X.; Hendrie, G.A.; Hendrie, D.; Sullivan, D.; Pratt, I.S.; Kerr, D.A.; Scott, J.A. Obesity, socio-demographic and attitudinal factors associated with sugar-sweetened beverage consumption: Australian evidence. Aust. N. Z. J. Public Health 2016, 40, 71-77. [CrossRef] [PubMed] 
19. Kit, B.K.; Fakhouri, T.H.I.; Park, S.; Neilsen, S.J.; Ogden, C.L. Trends in sugar-sweetened beverage consumption among youth and adults in the United States: 1999-2010. Am. J. Clin. Nutr. 2013, 98, 180-188. [CrossRef] [PubMed]

20. O'Leary, F.; Hattersley, L.; King, L.; Allman-Farinelli, M. Sugary drink consumption behaviours among young adults at university. Nutr. Diet. 2012, 69, 119-123. [CrossRef]

21. French, S.; Rosenberg, M.; Wood, L.; Maitland, C.; Shilton, T.; Pratt, I.S.; Buzzacott, P. Soft drink consumption patterns among Western Australians. J. Nutr. Educ. Behav. 2013, 45, 525-532. [CrossRef]

22. Park, S.; Onufrak, S.; Blanck, H.M.; Sherry, B. Characteristics associated with the consumption of sports and energy drinks among US adults: National Health Interview Survey 2010. J. Acad. Nutr. Diet. 2013, 113, 112-119. [CrossRef]

23. Friis, K.; Lyng, J.I.; Lasgaard, M.; Larsen, F.B. Energy drink consumption and the relation to socio-demographic factors and health behaviour among young adults in Denmark. A population based study. Eur. J. Public Health 2014, 24, 840-844. [CrossRef] [PubMed]

24. Wymond, B.S.; Dickinson, K.M.; Riley, M.D. Alcoholic beverage intake throughout the week and contribution to dietary energy intake in Australian adults. Public Health Nutr. 2016, 19, 2592-2602. [CrossRef]

25. Crowe-White, K.; O’Neil, C.E.; Parrott, J.S.; Benson-Davies, S.; Droke, E.; Gutschall, M.; Stote, K.S.; Wolfram, T.; Ziegler, P. Impact of 100\% fruit juice consumption on diet and weight status of children: An evidence-based review. Crit. Rev. Food Sci. Nutr. 2016, 56, 871-884. [CrossRef]

26. Wang, Y.; Lloyd, B.; Yang, M.; Davis, C.G.; Lee, S.G.; Lee, W.; Chung, S.J.; Chun, O. Impact of orange juice consumption on macronutrient and energy intakes and body composition in the US population. Public Health Nutr. 2012, 15, 2220-2227. [CrossRef] [PubMed]

27. Rose, A.M.; Williams, R.A.; Rengers, B.; Kennel, J.A.; Gunther, C. Determining attitudinal and behavioral factors concerning milk and dairy intake and their association with calcium intake in college students. Nutr. Res. Prac. 2018, 12, 143-148. [CrossRef] [PubMed]

28. Australian Bureau of Statistics 2018. National Health Survey: First Results, 2017-2018. Catalogue Number 4364.0.55.001. Available online: http://www.abs.gov.au (accessed on 15 April 2019).

29. Sharma, Y.; Miller, M.; Shahi, R.; Doyle, A.; Horwood, C.; Hakendorf, P.; Thompson, C. Vitamin C deficiency in Australian hospitalized patients: An observational study. Intern. Med. J. 2019, 49, 189-196. [CrossRef] [PubMed]

30. Australian Bureau of Statistics 2015. Australian Health Survey: Usual Nutrient Intakes, 2011-2012. Catalogue Number 4364.0.55.008. Available online: http://www.abs.gov.au (accessed on 15 April 2019).

31. Baird, D.L.; Syrette, J.; Hendrie, G.A.; Riley, M.D.; Bowen, J.; Noakes, M. Dairy food intake of Australian children and adolescents 2-16 years of age: 2007 Australian National Children's Nutrition and Physical Activity Survey. Public Health Nutr. 2012, 15, 2060-2073. [CrossRef] [PubMed]

32. Fayet-Moore, F. Effect of flavored milk vs plain milk on total milk intake and nutrient provision in children. Nutr. Rev. 2016, 74, 1-17. [CrossRef]

33. Chaloupka, F.J.; Powell, L.M.; Warner, K.E. The use of excise taxes to reduce tobacco, alcohol, and sugary beverage consumption. Annu. Rev. Public Health 2019, 40, 187-201. [CrossRef]

34. Veerman, J.L.; Sacks, G.; Antonopoulos, N.; Martin, J. The impact of a tax on sugar-sweetened beverages on health and health care costs: A modelling study. PLoS ONE 2016, 11, e0151460. [CrossRef]

35. Gupta, A.; Smithers, L.G.; Braunack-Mayer, A.; Harford, J. How much free sugar do Australians consume? Findings from a National survey. Aust. N. Z. J. Public Health 2018, 42, 533-540. [CrossRef]

36. Thow, A.M.; Downs, S.; Jan, S. A systematic review of the effectiveness of food taxes and subsidies to improve diets: Understanding the recent evidence. Nutr. Rev. 2014, 72, 551-565. [CrossRef]

37. Jithitikulchai, T.; Andreyeva, T. Sugar-sweetened beverage demand and tax simulation for Federal food assistance participants: A case study of two New England states. Appl. Health Econ. Health Policy 2018, 16, 549-558. [CrossRef] [PubMed]

38. Lei, L.; Rangan, A.; Flood, V.M.; Louie, J.C.Y. Dietary intake and food sources of added sugar in the Australian population. Br. J. Nutr. 2016, 115, 868-877. [CrossRef] [PubMed]

39. Leurs, L.J.; Schouten, L.J.; Goldbohm, R.A.; van den Brandt, P.A. Total fluid and specific beverage intake and mortality due to IHD and stroke in the Netherlands Cohort Study. Br. J. Nutr. 2010, 104, 1212-1221. [CrossRef] [PubMed] 
40. Drewnowski, A.; Rehm, C.D.; Constant, F. Water and beverage consumption among adults in the United States: Cross-sectional study using data from NHANES 2005-2010. BMC Public Health 2013, 13, 1068. [CrossRef] [PubMed]

41. Gazan, R.; Sondey, J.; Maillot, M.; Guelinckx, I.; Lluch, A. Drinking water intake is associated with higher diet quality among French adults. Nutrients 2016, 8, 689. [CrossRef] [PubMed]

42. Rodriguez-Ramirez, S.; de Cosio, T.G.; Mendez, M.A.; Tucker, K.L.; Mendez-Ramirez, I.; Hernandez-Cordero, S.; Popkin, B.M. A water and education provision intervention modifies the diet in overweight Mexican women in a randomized controlled trial. J. Nutr. 2015, 145, 1892-1899. [CrossRef]

43. Stookey, J.J.D. Negative, null and beneficial effects of drinking water on energy intake, energy expenditure, fat oxidation and weight change in randomized trials: A qualitative review. Nutrients 2016, 8, 19. [CrossRef]

44. Masood, A.; Alsheddi, L.; Alfayadh, L.; Bukhara, B.; Elawad, R.; Alfadda, A.A. Dietary and lifestyle factors serve as predictors of successful weight loss maintenance postbariatric surgery. J. Obes. 2019. [CrossRef] [PubMed]

45. Tate, D.F.; Turner-McGrievy, G.; Lyons, E.; Stevens, J.; Erickson, K.; Polzien, K.; Diamond, M.; Wang, X.; Popkin, B. Replacing caloric beverages with water or diet beverages for weight loss in adults: Main results of the Choose Healthy Options Consciously Everyday (CHOICE) randomized clinical trial. Am. J. Clin. Nutr. 2012, 95, 555-563. [CrossRef] [PubMed]

46. Nissensohn, M.; Sanchez-Villegas, A.; Galan, P.; Turrini, A.; Arnault, N.; Mistura, L.; Ortiz-Andrellucchi, A.; de Edelenyi, F.S.; D'Addezio, L.; Serra-Majem, L. Beverage consumption habits among the European population: Association with total water and energy intakes. Nutrients 2017, 9, 383. [CrossRef] [PubMed]

47. Levy, G.S.; Shrapnel, W.S. Quenching Australia's thirst: A trend analysis of water-based beverage sales from 1997 to 2011. Nutr. Diet. 2014, 71, 193-200. [CrossRef]

48. Shi, Z.; Ruel, G.; Dal Grande, E.; Pilkington, R.; Taylor, A.W. Soft drink consumption and multimorbidity among adults. Clin. Nutr. ESPEN 2015, 10, e71-e76. [CrossRef] [PubMed]

49. Lafontan, M.; Visscher, T.L.S.; Farpour-Lambert, N.; Yumak, V. Opportunities for intervention strategies for weight management: Global actions on fluid intake patterns. Obes. Facts 2015, 8, 54-76. [CrossRef] [PubMed]

50. Rozin, P.; Gohar, D. The pleasures and memories of food and meals. In Handbook of Behavior, Food and Nutrition; Preedy, V.R., Watson, R., Martin, C., Eds.; Springer: New York, NY, USA, 2011; pp. 659-672. [CrossRef]

51. Australian Bureau of Statistics 2014. Australian Health Survey: Users' Guide, 2011-2013. Catalogue Number 4363.0.55.001. Available online: http://www.abs.gov.au (accessed on 15 April 2019).

52. Rennie, K.L.; Coward, J.; Jebb, S.A. Estimating under-reporting of energy intake in dietary surveys using an individualised method. Br. J. Nutr. 2007, 97, 1169-1176. [CrossRef]

53. Patterson, R.E.; Pietinen, P. Assessment of nutritional status in individuals and populations. In Public Health Nutrition; Gibney, M.J., Margetts, B.M., Kearney, J.M., Arab, L., Eds.; Blackwell Science: Oxford, UK, 2004; pp. 66-84. 